\title{
Dissociation of C-Reactive Protein Levels from Long-Chain Omega-3 Fatty Acid Status and Antidepressant Response in Adolescents with Major Depressive Disorder: An Open-Label Dose- Ranging Trial
}

\author{
Robert K. McNamara ${ }^{1^{*}}$, Mary Perry ${ }^{2}$ and Barry Sears ${ }^{2}$ \\ ${ }^{1}$ Department of Psychiatry and Behavioral Neuroscience, University of Cincinnati College of Medicine, \\ Cincinnati $\mathrm{OH}$ 45219, USA \\ ${ }^{2}$ Inflammation Research Foundation, Marblehead, Massachusetts, USA
}

\begin{abstract}
Major depressive disorder (MDD) is associated with long-chain omega-3 (LCn-3) fatty acid deficits and indices of chronic sustained inflammation including elevated C-reactive protein (CRP) levels. The present study combined a case-control analysis and a prospective 10-week open-label fish oil (FO) supplementation trial to investigate the relationships among plasma phospholipid LC $n-3$ fatty acid levels, plasma CRP concentrations, and depressive symptoms in adolescent MDD patients. Compared with healthy controls $(n=20)$, MDD patients $(n=20)$ exhibited significantly lower EPA+DHA levels $(-62 \%, p \leq 0.0001)$ and a higher ratio of arachidonic acid $(A A)$ to EPA+DHA $(+78 \%$, $\mathrm{p}=0.0002)$. CRP concentrations did not differ between controls and MDD patients ( $0.16 \mathrm{vs} .0 .17 \mathrm{mg} / \mathrm{dL}, \mathrm{p}=0.96)$, and were positively correlated with depression symptom severity scores in MDD patients $(r=+0.55, \mathrm{p}=0.01)$. CRP concentrations were positively correlated with BMI in MDD patients $(r=+0.63, \mathrm{p}=0.005)$ and controls $(r=+0.69$, $\mathrm{p}=0.002)$. Low-dose $(2.4 \mathrm{~g} / \mathrm{d})$ and high-dose $(15 \mathrm{~g} / \mathrm{d}) \mathrm{FO}$ supplementation significantly increased EPA+DHA levels in MDD patients, but did not significantly alter CRP concentrations. Baseline and baseline-endpoint change in CRP levels were not correlated with baseline-endpoint reductions in depression severity. Together, these data demonstrate that the lower plasma phospholipid LC $n$-3 fatty acid composition exhibited by adolescent MDD patients is not associated with higher CRP levels, and that increasing LC $n-3$ fatty acid status reduces depression symptom severity independent of changes in CRP concentrations. Collectively, these data suggest that CRP concentrations are dissociable from LC $n$-3 fatty acid status and antidepressant response in adolescent MDD patients.
\end{abstract}

Keywords: Major depressive disorder, C-Reactive Protein (CRP), Omega-3 Fatty Acids, Fish oil, Docosahexaenoic acid (DHA), Eicosapentaenoic acid (EPA).

\section{INTRODUCTION}

Major depressive disorder (MDD) significantly increases the risk for cardiovascular diseases [1], and is associated with excess premature mortality due in part to cardiovascular disease [2,3]. Converging evidence suggests that a deficiency in long-chain omega-3 (LCn-3) fatty acids, including eicosapentaenoic acid (EPA, 20:5n-3) and docosahexaenoic acid (DHA, 22:6n-3), may represent a modifiable risk factor for MDD and cardiovascular-related mortality [4]. A body of translational data further suggests that pathophysiology of MDD [5-10] and cardiovascular morbidity and mortality [11-13] are associated with chronic low-grade inflammation, evidenced in part by elevated plasma concentrations of the acute phase protein C-reactive protein (CRP). Therefore, elevated CRP concentrations may represent a risk mechanism linking low LCn-3 fatty acid status, MDD, and cardiovascular disease.

*Address correspondence to this author at the Department of Psychiatry and Behavioral Neuroscience, University of Cincinnati College of Medicine, 260 Stetson Street, Cincinnati, OH 45219-0516, USA; Tel: 513-558-5601;

Fax: 513-558-4805; E-mail: robert.mcnamara@uc.edu
Existing evidence suggests that LC $n-3$ fatty acids and their bioactive metabolites have anti-inflammatory properties, whereas the metabolites of the omega- 6 fatty acid arachidonic acid (AA, 20:4n-6) are predominantly pro-inflammatory [14-17]. However, metabolites of the omega- 6 fatty acid homo- $\gamma$-linolenic acid (HGLA, 20:3n-6) have anti-inflammatory properties. Population studies have observed an independent inverse correlation between blood LC $n-3$ fatty acid levels and CRP levels among healthy adults [18-23] and in patients with coronary artery disease [24]. We demonstrated that chronic dietary $n-3$ fatty acid insufficiency leading to systemic LC $n-3$ fatty acid deficits significantly increased CRP concentrations in rat plasma [25]. Although case-control studies have consistently observed lower LC $n-3$ fatty acid levels in erythrocytes (red blood cells) and/or plasma phospholipids from MDD patients [26-31], the relationships among $\mathrm{LC} n-3$ fatty acid status, CRP concentrations, and depressive symptoms are poorly understood.

The present study combined a case-control analysis and prospective open-label dose-ranging fish oil (FO) supplementation trial to investigate the relationships 
among LC $n-3$ fatty acid status, CRP concentrations, and depression symptom severity in adolescent MDD patients. It was hypothesized that patients with MDD would exhibit LCn-3 fatty acid deficits and associated elevations in CRP compared with healthy controls, and that increasing patient $\mathrm{LC} n-3$ fatty acid status through FO supplementation would dose-dependently decrease CRP concentrations and depressive symptoms.

\section{MATERIALS AND METHODS}

\subsection{Subjects}

Written informed consent and assent were provided by a legal guardian and the subject, respectively, and all procedures were approved by the University of Cincinnati Institutional Review Board. Patients (ages 821 years) were diagnosed with MDD (DSM-IV-TR criteria), which was confirmed with the Washington University in St. Louis Kiddie Schedule for Affective Disorders and Schizophrenia (K-SADS) [32]. Patients were required to have a baseline score of $>28$ (i.e., symptomatic) on the Children Depression Rating Scale-Revised (CDRS-R) [33] despite being administered a standard therapeutic dose of a selective serotonin reuptake inhibitor (SSRI) for a minimum of 6 weeks (i.e., treatment-resistant). Patients were maintained on their current SSRI and dose over the course of this supplementation trial. Healthy controls with no personal history of any DSM-IV-TR Axis I disorder were recruited from the greater Cincinnati area. Subjects were excluded if they tested positive for pregnancy or illicit substance use or were currently taking LC $n-3$ fatty acid supplements. Cigarette smoking status and body mass index $\left(\mathrm{BMI}, \mathrm{kg} / \mathrm{m}^{2}\right)$ were also determined.

\subsection{Treatment}

Patients were randomized to open-label FO supplements (supplied by the Inflammation Research Foundation) at a fixed dose of either $2.4 \mathrm{~g} /$ day (LowDose: EPA $1.6 \mathrm{~g}$ + DHA $0.8 \mathrm{~g} ; 4$ capsules/d) or 15 g/day (High-Dose: EPA, $10.8 \mathrm{~g}$ + DHA $5.4 \mathrm{~g} ; 2$ tablespoons/day) for 10 weeks. Independent analysis of the fatty acid composition of the FO confirmed that it was composed of approximately 45\% EPA (20:5n-3) and $26 \%$ DHA $(22: 6 n-3)$ wt \% total fatty acids. Compliance was evaluated by determining capsule counts (low-dose) or bottle volumes (high-dose).

\subsection{Depression Symptom Ratings}

At baseline and all weekly visits, depression symptom severity was determined with the Children's
Depression Rating Scale-Revised (CDRS-R), a 17-item observer-rated questionnaire $[33,34]$, administered by experienced raters with established reliability (ICC > $0.8)$

\subsection{Fatty Acid Analysis}

At baseline and study endpoint (Week 10), whole venous blood $(10 \mathrm{ml})$ was collected into EDTA-coated BD Vacutainer tubes. Blood was centrifuged for $20 \mathrm{~min}$ $\left(1,500 \times g, 4^{\circ} \mathrm{C}\right)$, and plasma collected and stored at $80^{\circ} \mathrm{C}$. The gas chromatography procedure used to determine phospholipid fatty acid composition has been described in detail previously [35]. Briefly, fatty acid methyl esters (FAMEs) were analyzed using an HP 6890/5973 gas chromatograph/mass selective detector (Agilent Technologies, Santa Clara, CA). The column used to separate FAME's was an Agilent J\&W DB-FFAP $15 \mathrm{~m} \times 0.1 \mathrm{~mm}$ with $0.1 \mathrm{um}$ of film thickness. Helium was used as carrier gas at a flow rate of 17.6 $\mathrm{ml} / \mathrm{min}$ and a constant pressure of 53.8 psi. Fatty acid identification was based on retention times of authenticated fatty acid methyl ester standards (GLC 473B) and controls (GLC 462 and GLC 463) to ensure reproducibility (NuCheck Prep, Elysian, MN). Data are expressed as weight percent of total fatty acid pool ( $\mathrm{mg}$ fatty acid/100 mg fatty acids). Primary measures of interest were EPA, DHA, homo- $\gamma$-linolenic acid (20:3n6, HGLA), AA, and the AA/DHA, AA/EPA, and $A A / E P A+D H A$ ratios.

\subsection{Plasma CRP Levels}

Plasma CRP levels were determined using a highsensitivity quantitative enzyme immunoassay according to manufacturers instructions (SYNCHRON ${ }^{\circledR}$ Systems Inc.). The lower limit of detection was $0.02 \mathrm{mg} / \mathrm{dL}$, and the average intra-assay and inter-assay coefficients of variation were below $5 \%$ and $10 \%$, respectively. Cardiovascular risk categories based on CRP concentrations were also evaluated (Low-to-mild risk: $\leq 0.11 \mathrm{mg} / \mathrm{dL}$; Moderate risk: $0.12-0.19 \mathrm{mg} / \mathrm{dL}$, and High risk: $\geq 0.2 \mathrm{mg} / \mathrm{dL}$ ) [36].

\subsection{Statistical Analyses}

Case-control differences in primary outcome measures were evaluated using unpaired $t$-tests (2tailed, $\alpha=0.05)$ for continuous variables and Chisquared tests (2-tailed, $\alpha=0.05$ ) for dichotomous variables. Analysis of gender effects was performed with a two-way ANOVA using gender (male, female) and group (control, MDD) as the main factors. Baseline-endpoint changes in primary outcome 
measures were evaluated with a two-way ANOVA, with dose (low-dose, high-dose) and study time point (baseline, endpoint) as the main factors. For depressive symptom scores (CDRS) obtained at weekly visits, a repeated measures ANOVA was used on the intent-to-treat (ITT) population which included all patients who received at least one dose of study medication and also had at least one post-baseline assessment. Parametric linear regression analyses were performed to determine the interrelationship among selected fatty acids levels, CRP concentrations, and/or selected clinical variables (2-tailed, $\alpha=0.05$ ). Statistical analyses were performed using GB-STAT (V.10, Dynamic Microsystems, Inc., Silver Springs MD).

\section{RESULTS}

\subsection{Case-Control Analysis}

Patient and control demographic, fatty acid, and CRP data are presented in Table 1. The LCn-3 fatty acids EPA and DHA, were both significantly lower in MDD patients, and the omega- 6 fatty acids $A A$ and HGLA were not different (Table 1). The ratios of AA to EPA and/or DHA were significantly greater in MDD patients. CRP concentrations did not differ significantly between groups, and the relative distribution of CRP values in low ( $n=12$ vs. $n=12, p=1.0)$, moderate $(n=4$ vs. $n=4, p=1.0)$, and high ( $n=4$ vs. $n=4, p=1.0)$ risk categories did not differ between patients and controls.

Table 1: Case-Control Comparisons

\begin{tabular}{|c|c|c|c|}
\hline Variable $^{1}$ & Controls $(n=20)$ & $\operatorname{MDD}(n=20)$ & P-value $^{2}$ \\
\hline Age (yrs) & $17.3 \pm 0.9$ & $16.1 \pm 0.7$ & 0.14 \\
\hline \multicolumn{4}{|l|}{ Gender $(n)$} \\
\hline Male & 8 & 6 & 0.74 \\
\hline Female & 12 & 14 & \\
\hline \multicolumn{4}{|l|}{ Race $(n)$} \\
\hline Caucacian & 14 & 19 & 0.10 \\
\hline African American & 2 & 1 & \\
\hline Hispanic & 4 & 0 & \\
\hline Height $(\mathrm{cm})$ & $168.1 \pm 2.4$ & $163.2 \pm 3.1$ & 0.17 \\
\hline Weight (kg) & $68.0 \pm 3.9$ & $64.4 \pm 4.4$ & 0.56 \\
\hline BMI $\left(\mathrm{kg} / \mathrm{m}^{2}\right)$ & $24.0 \pm 1.3$ & $24.2 \pm 1.6$ & 0.91 \\
\hline Smoking status (current) $(n)$ & 2 & 2 & 1.0 \\
\hline Age at Onset (yrs) & - & $13.1 \pm 0.7$ & - \\
\hline CDRS-R Total Score & - & $34.7 \pm 1.0$ & - \\
\hline \multicolumn{4}{|l|}{ SSRI $(n)$} \\
\hline Prozac & - & 9 & - \\
\hline Celexa & - & 3 & - \\
\hline Lexapro & - & 2 & - \\
\hline Zoloft & - & 6 & - \\
\hline \multicolumn{4}{|l|}{ Fatty Acids (wt \% TTL) } \\
\hline Homo- $\gamma$-linolenic acid $(20: 3 n-6)$ & $1.6 \pm 0.1$ & $1.5 \pm 0.1$ & 0.61 \\
\hline Arachidonic acid (AA, 20:4 n-6) & $9.6 \pm 0.4$ & $9.7 \pm 0.6$ & 0.99 \\
\hline Eicosapentaenoic acid (EPA, 20:5 n-3) & $0.42 \pm 0.0$ & $0.09 \pm 0.0$ & 0.0001 \\
\hline Docosahexaenoic acid (DHA, 22:6 n-3) & $0.49 \pm 0.3$ & $0.28 \pm 0.1$ & 0.01 \\
\hline $\mathrm{EPA}+\mathrm{DHA}$ & $0.89 \pm 0.1$ & $0.34 \pm 0.1$ & 0.0001 \\
\hline$A A: D H A$ & $24.6 \pm 3.2$ & $63.3 \pm 10.8$ & 0.001 \\
\hline AA:EPA & $27.7 \pm 3.5$ & $192.8 \pm 17.6$ & 0.0001 \\
\hline$A A: E P A+D H A$ & $12.9 \pm 1.6$ & $57.4 \pm 10.8$ & 0.0002 \\
\hline $\mathrm{CRP}(\mathrm{mg} / \mathrm{dL})$ & $0.16 \pm 0.2$ & $0.17 \pm 0.2$ & 0.96 \\
\hline Low risk $(\leq 0.11 \mathrm{mg} / \mathrm{dL})(n)$ & 12 & 12 & 1.0 \\
\hline Moderate risk $(0.12-0.19 \mathrm{mg} / \mathrm{dL})(n)$ & 4 & 4 & 1.0 \\
\hline High risk $(\geq 0.2 \mathrm{mg} / \mathrm{dL})(n)$ & 4 & 4 & 1.0 \\
\hline
\end{tabular}

${ }^{1} V$ alues are group mean \pm S.E.M.

22-tailed t-test or Chi-squared test. 
Among MDD patients $(n=20)$, CRP was positively correlated with depression symptom severity scores $(r$ $=+0.55, \mathrm{p}=0.01)$ and BMI $(r=+0.63, \mathrm{p}=0.005)$, and there was a trend for a positive correlation between $\mathrm{EPA}+\mathrm{DHA}$ and CRP $(r=+0.41, \mathrm{p}=0.09)$ but not other fatty acid measures. Among controls $(n=20)$, CRP was positively correlated with $\mathrm{BMI}(r=+0.69, \mathrm{p}=0.002)$ but not EPA+DHA $(r=+0.16, p=0.52)$. Among all subjects $(n=40)$, CRP concentrations were positively correlated with EPA $(r=+0.41, \mathrm{p}=0.03)$ and there was a trend for positive correlation with EPA+DHA $(r=+0.28, \mathrm{p}=0.09)$ but not other fatty acid measures including HGLA ( $r=$ $+0.17, \mathrm{p}=0.30)$ and the AA/EPA ratio $(r=+0.02$, $\mathrm{p}=0.89$ ).

\subsection{FO Supplementation Trial}

Of the 20 patients randomized to treatment, a total of 14 patients completed the 10-week trial (low-dose, $\mathrm{n}=7$; high-dose, $\mathrm{n}=7$ ). Three patients were lost to follow-up post-randomization, and 3 patients terminated study participation early (2 patients in the low-dose group experienced a worsening of depressive symptoms and 1 patient declined to continue participation). The last available post-baseline CDRS score was used for patients with early termination. Based on capsule counts (low-dose) or bottle volumes (high-dose) at weekly visits, there was a compliance rate of $92 \%$ for the low-dose group and $97 \%$ for the high-dose group.

Primary outcome measures at baseline and endpoint (10 week) in patients treated with low-dose or high-dose FO are presented in Table 2. Both low-dose and high-dose FO supplementation significantly increased EPA+DHA composition, and reduced the ratio of AA to EPA and/or DHA. Baseline CDRS-R total scores in low-dose and high-dose groups did not differ significantly $(p=0.94)$. For CDRS-R total scores, there was a significant main effect of time $(p=0.0001)$, and the main effect of dose $(p=0.83)$ and the Time $x$ Dose interaction $(p=0.65)$ were not significant. In the ITT analysis, baseline CDRS-R total scores declined significantly in the high-dose group $(-40 \%, p=0.0001)$ and there was a trend for a decrease in the low-dose group $(-20 \%, p=0.06)$ at endpoint. After removal of the $\mathrm{n}=3$ patients in the low-dose group that did not complete the 10 week treatment trial, baseline CDRS-R total scores decreased significantly at endpoint $(-27 \%$, $\mathrm{p}=0.002$ ).

Neither low-dose nor high-dose FO supplementation significantly altered CRP concentrations, and the main effect of dose and the dose by time interaction were not significant. CRP concentrations exhibited nonsignificant increases in both low-dose $(+36 \%, p=0.51)$ and high-dose $(+25 \%, p=0.62)$ groups. Baseline CRP levels were not correlated with baseline-endpoint change in CDRS total scores $(r=+0.12, \mathrm{p}=0.71)$. At study endpoint, CRP concentrations were positively correlated with BMI $(r=+0.54, \mathrm{p}=0.04)$ but not CDRS total scores $(r=+0.01, \mathrm{p}=0.96)$, and there was a trend for a negative correlation between endpoint CRP and EPA+DHA $(r=-0.52, \mathrm{p}=0.06)$. There was a trend for a negative correlation between baseline-endpoint change in CRP and baseline-endpoint change in HGLA ( $r=-$ $0.52, p=0.12)$. There were trends for a positive correlation between baseline-endpoint change in CDRS total scores and baseline-endpoint change in HGLA $(r=+0.52, \mathrm{p}=0.06)$, but not for EPA+DHA $(r=-$ $0.04, \mathrm{p}=0.88)$ and the AA/EPA+DHA $(r=-0.13, \mathrm{p}=0.66)$ and AA/EPA $(r=-0.03, \mathrm{p}=0.90)$ ratios.

\section{DISCUSSION}

To our knowledge, this is the first study to investigate the relationships among $\mathrm{LC} n-3$ fatty acid status, CRP levels, and depressive symptoms in MDD patients. Consistent with prior case-control studies, the present study found that patients with MDD exhibited significant EPA+DHA deficits compared with healthy controls. This deficit could not be attributed to group differences in age, gender, BMI, or cigarette smoking. Contrary to our hypothesis, however, plasma CRP concentrations were not elevated in MDD patients compared with healthy controls, and were not significantly correlated with EPA+DHA levels. We did find that CRP concentrations were positively correlated with depression symptom severity scores in patients, and consistent with prior reports [37,38], were positively correlated with $\mathrm{BMI}$ in both patients and controls. Following 10-week FO supplementation, plasma phospholipid EPA+DHA levels increased significantly in MDD patients receiving low-dose or high-dose FO to levels $\sim 3.5$-fold greater than observed in healthy controls. Contrary to our hypothesis, however, we did not observe significant baselineendpoint decreases in CRP levels despite elevations in $\mathrm{EPA}+\mathrm{DHA}$ and reductions in depressive symptoms. Collectively, these data demonstrate that lower LCn-3 fatty acid status observed in adolescent MDD patients is not associated with greater CRP levels, and that increasing LC $n-3$ fatty acid status reduces depression symptom severity but not CRP concentrations.

This study has several important limitations. First, patients were being treated with an SSRI prior to and 
Table 2: Effects of Fish Oil Supplementation

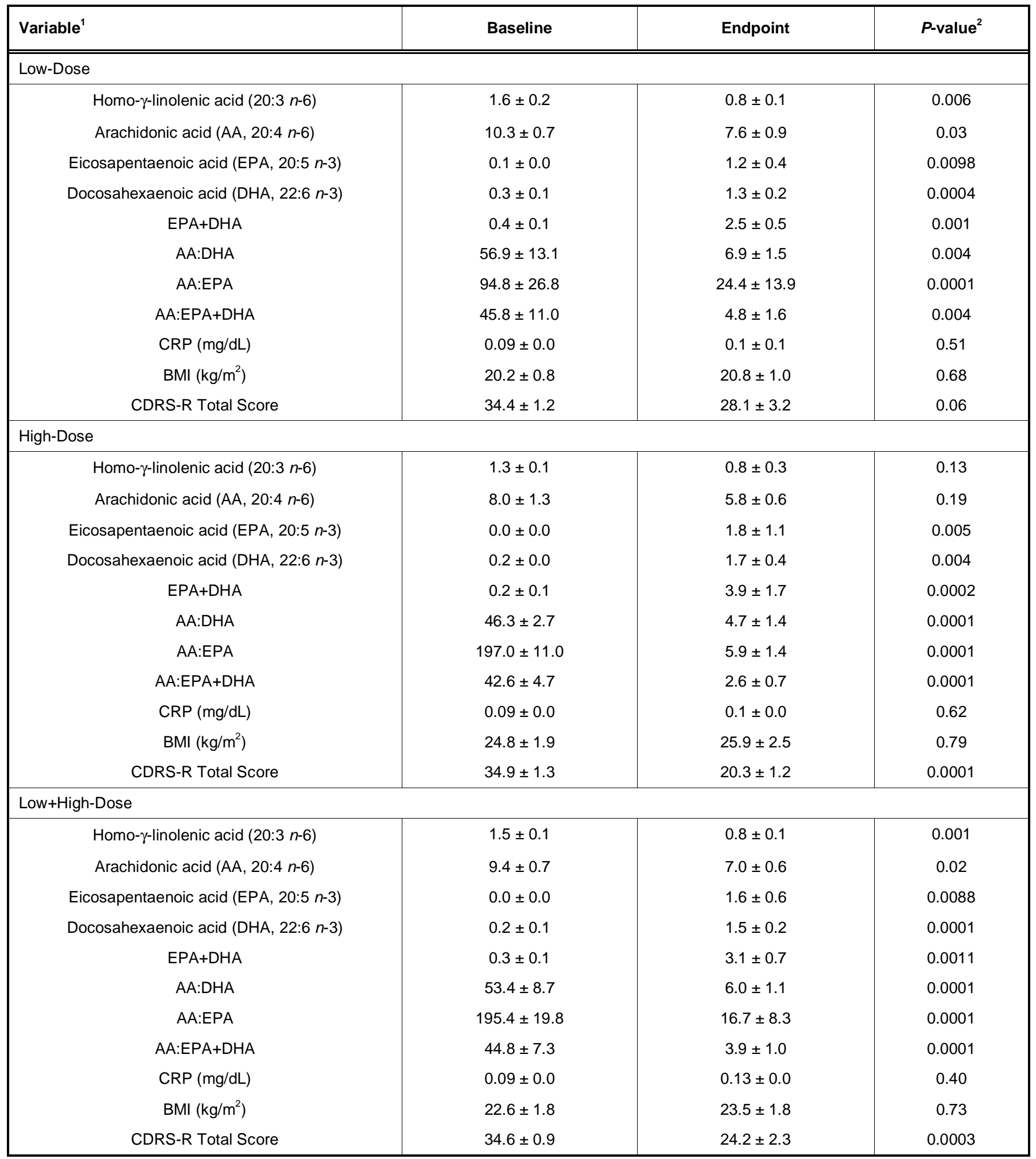

${ }^{1}$ Values are group mean \pm S.E.M.

${ }^{2} 2$-tailed $t$-tests.

during study participation. Therefore, it is possible that SSRI effects on primary outcome measures precluded observation of more robust group differences. For example, a prospective study found that SSRI treatment reduced CRP levels in MDD patients [39], though other studies found that SSRI treatment increased [40] or did not alter [41] CRP levels. Second, this study enrolled predominantly adolescent MDD 
patients (age range: 8-21 years), and prior population studies observing associations between CRP concentrations and depression were conducted in adults subjects [5-8]. Third, the relatively small number of subjects randomized to each treatment group may have been underpowered to detect statistically significant baseline-endpoint changes in CRP concentrations. However, we did not observe baselineendpoint changes in CRP after combining both dose groups, and detected trends for increased CRP levels. Fourth, the intervention trial design was open-label, and the observed baseline-endpoint changes in primary outcome measures should be viewed as preliminary. Fifth, the duration of FO supplementation was relatively short (10 weeks), and greater changes in CRP concentrations may require a longer supplementation period. Therefore, larger and longer controlled studies employing older medication-free MDD patients with high CRP concentrations are warranted to extend and confirm the present findings.

The observation that adolescent MDD patients exhibited robust LC $n-3$ fatty acid deficits compared with healthy adolescent controls is consistent with prior adult case-control studies [26-31]. However, plasma CRP concentrations did not differ significantly between MDD patients and healthy controls and were not inversely correlated with EPA+DHA levels. These data suggest that low LCn-3 fatty acid status is not associated with elevated CRP concentrations. This finding is consistent with two prior studies findings that lower EPA+DHA levels were not associated with group differences in CRP levels in depressed versus nondepressed cardiac patients [42] or among elderly subjects [43]. Together, these data do not support the observation of an inverse correlation between blood LC $n-3$ fatty acids and CRP levels in healthy adult populations [18-23]. Furthermore, the present data suggest that the inverse relationship between CRP concentrations and depression symptom severity in MDD patients at baseline is not mediated by lower LC $n-3$ fatty acid levels.

The observation that 10-week FO supplementation, and associated increases in LC $n-3$ fatty acid status, did not significantly reduce CRP levels in MDD patients is consistent with prior FO trials in healthy adult subjects [44-46] and patients with cardiovascular disease [47]. Indeed, we observed non-significant increases in CRP concentrations in low-dose $(+36 \%, p=0.51)$ and highdose $(+25 \%, p=0.62)$ FO groups. It is of interest, therefore, that a prior FO intervention trial $(5.2 \mathrm{~g} / \mathrm{d}$ for 12 weeks) also observed a non-significant trend for increased CRP concentrations $(+9 \%)$ in patients with a prior myocardial infarction [47]. These data suggest that acute FO supplementation is not efficacious for reducing CRP concentrations in different populations including MDD patients. One potential mechanism that may account for increasing versus decreasing CRP concentrations following FO supplementation is an elevation in lipid peroxidation $[48,49]$. Additionally or alternatively, FO supplementation was associated with decreases in the omega- 6 fatty acid homo- $\gamma$-linolenic acid (HGLA, 20:3n-6), which has anti-inflammatory properties, and we observed a trend for an inverse correlation between baseline-endpoint changes in CRP and HGLA. Additional studies will be required to investigate these and other potential mechanisms.

High-dose FO supplementation significantly reduced depression symptom severity scores $(-40 \%$, $\mathrm{p}<0.0001)$, and there was a trend in the low-dose FO group $(-20 \%, p=0.06)$. This observation is consistent with prior studies finding that FO supplementation reduces depression symptom severity in adolescent [50,51] and adult [52-55] patients with mood disorders. Although baseline CDRS scores were positively correlated with CRP concentrations, the baselineendpoint reduction in CDRS scores was not associated with changes in CRP levels and endpoint CDRS scores were not correlated with endpoint CRP levels. These data suggest that the antidepressant effects of FO supplementation are not mediated by reducing CRP levels. This observation is in general agreement with prior studies finding that serum CRP concentrations are poorly correlated SSRI treatment response in MDD patients $[39,40,56]$ and in depressed patients with coronary heart disease [57]. Furthermore, a prospective surveillance study found that CRP concentrations were not associated with treatmentemergent increases in depressive symptoms in hepatitis C patients following interferon-alpha administration [35]. Together, these findings suggest that plasma CRP concentrations are not a suitable biomarker of vulnerability to inflammation-induced depression or antidepressant treatment response.

In conclusion, the present findings in adolescent MDD patients support previous case-control studies finding that adult MDD patients exhibit LC $n-3$ fatty acid deficits and demonstrate that low LCn-3 fatty acid status is not associated with greater CRP concentrations. The present findings further demonstrate that adjunctive FO supplementation significantly increases LC $n-3$ fatty acid status and decreases depression symptom severity but does not 
alter CRP concentrations. Although additional research is needed to elucidate the pathogenic mechanisms linking low LCn-3 fatty acid status and mood dysregulation, the present data suggest that elevated CRP concentrations is not a mediating mechanism.

\section{ACKNOWLEDGEMENTS}

Funding for this study was provided in part by NIMH Grant $\mathrm{MH} 024773$ and an investigator-initiated grant from the Inflammation Research Foundation to R.K.M. The NIH and the Inflammation Research Foundation had no further role in study design; in the collection, analysis and interpretation of data; in the writing of the report; and in the decision to submit the paper for publication. The authors thank Fermin Castro for his technical assistance.

\section{REFERENCES}

[1] Van der Kooy $K$, van Hout $H$, Marwijk $H$, Marten $H$, Stehouwer C, Beekman A. Depression and the risk for cardiovascular diseases: systematic review and meta analysis. Int J Geriatr Psychiatry 2007; 22: 613-26. http://dx.doi.org/10.1002/gps.1723

[2] Angst F, Stassen HH, Clayton PJ, Angst J. Mortality of patients with mood disorders: follow-up over 34-38 years. J Affect Disord 2002; 68: 167-81. http://dx.doi.org/10.1016/S0165-0327(01)00377-9

[3] Osby U, Brandt L, Correia N, Ekbom A, Sparén P. Excess mortality in bipolar and unipolar disorder in Sweden. Arch Gen Psychiatry 2001; 58: 844-50.

http://dx.doi.org/10.1001/archpsyc.58.9.844

McNamara RK. Membrane omega-3 fatty acid deficiency as a preventable risk factor for comorbid coronary heart disease in major depressive disorder. Cardiovasc Psychiatry Neurol 2009; 9: 1-13.

http://dx.doi.org/10.1155/2009/362795

[5] Danner M, Kasl SV, Abramson JL, Vaccarino V. Association between depression and elevated C-reactive protein. Psychosom Med 2003; 65: 347-56. http://dx.doi.org/10.1097/01.PSY.0000041542.29808.01

Ford DE, Erlinger TP. Depression and C-reactive protein in US adults: data from the Third National Health and Nutrition Examination Survey. Arch Intern Med 2004; 164: 1010-4. http://dx.doi.org/10.1001/archinte.164.9.1010

[7] Howren MB, Lamkin DM, Suls J. Associations of depression with C-reactive protein, IL-1, and IL-6: a meta-analysis. Psychosom Med 2009; 71: 171-86. http://dx.doi.org/10.1097/PSY.0b013e3181907c1b

[8] Kling MA, Alesci S, Csako G, et al. Sustained low-grade proinflammatory state in unmedicated, remitted women with major depressive disorder as evidenced by elevated serum levels of the acute phase proteins $\mathrm{C}$-reactive protein and serum amyloid A. Biol Psychiatry 2007; 62: 309-13. http://dx.doi.org/10.1016/j.biopsych.2006.09.033

[9] McNamara RK, Lotrich FE. Elevated immune-inflammatory signaling in mood disorders: A new therapeutic target? Expert Rev Neurother 2012; 12: 1143-61. http://dx.doi.org/10.1586/ern.12.98

[10] Liukkonen T, Silvennoinen-Kassinen S, Jokelainen J, et al. The association between $\mathrm{C}$-reactive protein levels and depression: Results from the northern Finland 1966 birth cohort study. Biol Psychiatry 2006; 60: 825-30.

http://dx.doi.org/10.1016/j.biopsych.2006.02.016
Albert CM, Ma J, Rifai N, Stampfer MJ, Ridker PM. Prospective study of C-reactive protein, homocysteine, and plasma lipid levels as predictors of sudden cardiac death. Circulation 2002; 105: 2595-9.

http://dx.doi.org/10.1161/01.CIR.0000017493.03108.1C

[12] Blake GJ, Ridker PM. C-reactive protein and other inflammatory risk markers in acute coronary syndromes. $J$ Am Coll Cardiol 2003; 41: 37S-42S. http://dx.doi.org/10.1016/S0735-1097(02)02953-4

[13] Danesh J, Whincup $\mathrm{P}$, Walker $\mathrm{M}$, et al. Low grade inflammation and coronary heart disease: prospective study and updated meta-analyses. BMJ 2000; 321: 199-204. http://dx.doi.org/10.1136/bmj.321.7255.199

[14] Bagga D, Wang L, Farias-Eisner R, Glaspy JA, Reddy ST. Differential effects of prostaglandin derived from omega- 6 and omega-3 polyunsaturated fatty acids on COX-2 expression and IL-6 secretion. Proc Natl Acad Sci USA 2003; 100: $1751-6$

http://dx.doi.org/10.1073/pnas.0334211100

[15] Calder PC. The relationship between the fatty acid composition of immune cells and their function Prostaglandins Leukot Essent Fatty Acids 2008; 79: 101-8. http://dx.doi.org/10.1016/i.plefa.2008.09.016

[16] Groeger AL, Cipollina C, Cole MP, et al. Cyclooxygenase-2 generates anti-inflammatory mediators from omega- 3 fatty acids. Nat Chem Biol 2010; 6: 433-41. http://dx.doi.org/10.1038/nchembio.367

[17] Hong S, Gronert K, Devchand PR, Moussignac RL, Serhan $\mathrm{CN}$. Novel docosatrienes and 17S-resolvins generated from docosahexaenoic acid in murine brain, human blood, and glial cells. Autacoids in anti-inflammation. J Biol Chem 2003; 278: $14677-87$.

http://dx.doi.org/10.1074/jbc.M300218200

[18] Reinders I, Virtanen JK, Brouwer IA, Tuomainen TP. Association of serum n-3 polyunsaturated fatty acids with Creactive protein in men. Eur J Clin Nutr 2012; 66: 736-41. http://dx.doi.org/10.1038/ejcn.2011.195

[19] Murakami K, Sasaki S, Takahashi $Y$, et al. Total n-3 polyunsaturated fatty acid intake is inversely associated with serum C-reactive protein in young Japanese women. Nutr Res 2008; 28: 309-14. http://dx.doi.org/10.1016/j.nutres.2008.03.008

[20] Niu K, Hozawa A, Kuriyama S, et al. Dietary long-chain n-3 fatty acids of marine origin and serum C-reactive protein concentrations are associated in a population with a diet rich in marine products. Am J Clin Nutr 2006; 84: 223-9.

[21] Pischon T, Hankinson SE, Hotamisligil GS, Rifai N, Willett WC, Rimm EB. Habitual dietary intake of $n-3$ and $n-6$ fatty acids in relation to inflammatory markers among US men and women. Circulation 2003; 108: 155-60. http://dx.doi.org/10.1161/01.CIR.0000079224.46084.C2

[22] Kalogeropoulos N, Panagiotakos DB, Pitsavos C, et al Unsaturated fatty acids are inversely associated and $n-6 / n-3$ ratios are positively related to inflammation and coagulation markers in plasma of apparently healthy adults. Clin Chim Acta 2010; 411: 584-91.

http://dx.doi.org/10.1016/j.cca.2010.01.023

[23] Lopez-Garcia E, Schulze MB, Manson JE, et al. Consumption of (n-3) fatty acids is related to plasma biomarkers of inflammation and endothelial activation in women. J Nutr 2004; 134: 1806-11.

[24] Farzaneh-Far R, Harris WS, Garg S, Na B, Whooley MA. Inverse association of erythrocyte n-3 fatty acid levels with inflammatory biomarkers in patients with stable coronary artery disease: The Heart and Soul Study. Atherosclerosis 2009; 205: 538-43. http://dx.doi.org/10.1016/j.atherosclerosis.2008.12.013

[25] McNamara RK, Rider T, Jandacek R, Tso P, Cole-Strauss A. Lipton JW. Omega-3 fatty acid deficiency increases 
constitutive pro-inflammatory cytokine production in rats: Relationship with central serotonin turnover. Prostaglandins Leukot Essent Fatty Acids 2010; 83: 185-91. http://dx.doi.org/10.1016/j.plefa.2010.08.004

[26] Edwards R, Peet M, Shay J, Horrobin D. Omega-3 polyunsaturated fatty acid levels in the diet and in red blood cell membranes of depressed patients. J Affect Disord 1998; 48: $149-55$.

http://dx.doi.org/10.1016/S0165-0327(97)00166-3

[27] Peet M, Murphy B, Shay J, Horrobin D. Depletion of omega-3 fatty acid levels in red blood cell membranes of depressive patients. Biol Psychiatry 1998; 43: 315-9. http://dx.doi.org/10.1016/S0006-3223(97)00206-0

[28] Assies J, Pouwer F, Lok A, et al. Plasma and erythrocyte fatty acid patterns in patients with recurrent depression: a matched case-control study. PLoS One 2010; 5: e10635. http://dx.doi.org/10.1371/journal.pone.0010635

[29] Riemer S, Maes M, Christophe A, Rief W. Lowered omega-3 PUFAs are related to major depression, but not to somatization syndrome. J Affect Disord 2010; 123: 173-80. http://dx.doi.org/10.1016/j.jad.2009.08.004

[30] Lin PY, Huang SY, Su KP. A meta-analytic review of polyunsaturated fatty acid compositions in patients with depression. Biol Psychiatry 2010; 68: 140-7. http://dx.doi.org/10.1016/j.biopsych.2010.03.018

[31] McNamara RK, Jandacek R, Rider T, Tso P, Dwivedi Y, Pandey GN. Selective deficits in erythrocyte docosahexaenoic acid composition in adult patients with bipolar disorder and major depressive disorder. J Affect Disord 2010; 126: 303-11. http://dx.doi.org/10.1016/j.jad.2010.03.015

[32] Geller B, Zimerman B, Williams $M$ et al. Reliability of the Washington University in St. Louis Kiddie Schedule for Affective Disorders and Schizophrenia (WASH-U-KSADS) mania and rapid cycling sections. J Am Acad Child Adolesc Psychiatry 2001; 40: 450-5. http://dx.doi.org/10.1097/00004583-200104000-00014

[33] Poznanski EO, Cook SC, Carroll BJ, Corzo H. Use of the Children's Depression Rating Scale in an inpatient psychiatric population. J Clin Psychiatry 1983; 44:200-3.

[34] Mayes TL, Bernstein IH, Haley CL, Kennard BD, Emslie GJ. Psychometric properties of the Children's Depression Rating Scale-Revised in adolescents. J Child Adolesc Psychopharmacol 2010; 20: 513-6. http://dx.doi.org/10.1089/cap.2010.0063

[35] Lotrich FE, Sears B, McNamara RK. Elevated ratio of arachidonic acid to long-chain omega- 3 fatty acids predicts depression development following interferon-alpha treatment: Relationship with interleukin-6. Brain Behav Immun 2013; 31: 48-53. http://dx.doi.org/10.1016/j.bbi.2012.08.007

[36] Ridker PM. High-sensitivity C-reactive protein: Potential adjunct for global risk assessment in the primary prevention of cardiovascular disease. Circulation 2001; 103: 1813-8. http://dx.doi.org/10.1161/01.CIR.103.13.1813

[37] Visser M, Bouter LM, McQuillan GM, Wener MH, Harris TB. Elevated $C$-reactive protein levels in overweight and obese adults. JAMA 1999; 282: 2131-5. http://dx.doi.org/10.1001/jama.282.22.2131

[38] Visser M, Bouter LM, McQuillan GM, Wener MH, Harris TB. Low-grade systemic inflammation in overweight children. Pediatrics 2001; 107: E13. http://dx.doi.org/10.1542/peds.107.1.e13

[39] Tuglu C, Kara SH, Caliyurt O, Vardar E, Abay E. Increased serum tumor necrosis factor-alpha levels and treatment response in major depressive disorder. Psychopharmacology (Berl) 2003; 170: 429-33. http://dx.doi.org/10.1007/s00213-003-1566-z
[40] Chang HH, Lee IH, Gean PW, et al. Treatment response and cognitive impairment in major depression: association with Creactive protein. Brain Behav Immun 2012; 26: 90-5. http://dx.doi.org/10.1016/..bbi.2011.07.239

[41] Hamer M, Batty GD, Marmot MG, Singh-Manoux A, Kivimäki M. Anti-depressant medication use and C-reactive protein: results from two population-based studies. Brain Behav Immun 2011; 25: 168-73. http://dx.doi.org/10.1016/j.bbi.2010.09.013

[42] Schins A, Crijns HJ, Brummer RJ, et al. Altered omega-3 polyunsaturated fatty acid status in depressed postmyocardial infarction patients. Acta Psychiatr Scand 2007; 115: $35-40$

http://dx.doi.org/10.1111/j.1600-0447.2006.00830.x

[43] Tiemeier H, van Tuijl HR, Hofman A, Kiliaan AJ, Breteler MM. Plasma fatty acid composition and depression are associated in the elderly: the Rotterdam Study. Am J Clin Nutr 2003; 78: 40-6.

[44] Geelen A, Brouwer IA, Schouten EG, Kluft C, Katan MB, Zock PL. Intake of n-3 fatty acids from fish does not lower serum concentrations of $\mathrm{C}$-reactive protein in healthy subjects. Eur J Clin Nutr 2004; 58: 1440-2. http://dx.doi.org/10.1038/sj.ejen.1601986

[45] Madsen T, Christensen JH, Blom M, Schmidt EB. The effect of dietary $\mathrm{n}-3$ fatty acids on serum concentrations of Creactive protein: a dose-response study. $\mathrm{Br} \mathrm{J}$ Nutr 2003; 89 : 517-22.

http://dx.doi.org/10.1079/BJN2002815

[46] Skulas-Ray AC, Kris-Etherton PM, Harris WS, Vanden Heuvel JP, Wagner PR, West SG. Dose-response effects of omega-3 fatty acids on triglycerides, inflammation, and endothelial function in healthy persons with moderate hypertriglyceridemia. Am J Clin Nutr 2011; 93: 243-52. http://dx.doi.org/10.3945/ajcn.110.003871

[47] Madsen T, Christensen JH, Schmidt EB. C-reactive protein and n-3 fatty acids in patients with a previous myocardial infarction: a placebo-controlled randomized study. Eur J Nutr 2007; 46: 428-30.

http://dx.doi.org/10.1007/s00394-007-0673-8

[48] Meydani M, Natiello F, Goldin B, et al. Effect of long-term fish oil supplementation on vitamin $\mathrm{E}$ status and lipid peroxidation in women. J Nutr 1991; 121: 484-91.

[49] Minoguchi K, Yokoe T, Tanaka A, et al. Association between lipid peroxidation and inflammation in obstructive sleep apnoea. Eur Respir J 2006; 28: 378-85. http://dx.doi.org/10.1183/09031936.06.00084905

[50] Nemets H, Nemets B, Apter A, Bracha Z, Belmaker RH Omega-3 treatment of childhood depression: a controlled, double-blind pilot study. Am J Psychiatry 2006; 163: 1098100. http://dx.doi.org/10.1176/appi.ajp.163.6.1098

[51] Clayton EH, Hanstock TL, Hirneth SJ, Kable CJ, Garg ML, Hazell PL. Reduced mania and depression in juvenile bipolar disorder associated with long-chain omega-3 polyunsaturated fatty acid supplementation. Eur J Clin Nutr 2009; 63: 1037-40.

http://dx.doi.org/10.1038/ejcn.2008.81

[52] Appleton KM, Rogers PJ, Ness AR. Updated systematic review and meta-analysis of the effects of $n-3$ long-chain polyunsaturated fatty acids on depressed mood. Am J Clin Nutr 2010; 91: 757-70 http://dx.doi.org/10.3945/ajcn.2009.28313

[53] Sarris J, Mischoulon D, Schweitzer I. Omega-3 for bipolar disorder: meta-analyses of use in mania and bipolar depression. J Clin Psychiatry 2012; 73: 81-6. http://dx.doi.org/10.4088/JCP.10r06710

[54] Freeman MP, Hibbeln JR, Wisner KL, et al. Omega-3 fatty acids: evidence basis for treatment and future research in psychiatry. J. Clin. Psychiatry 2006; 67: 1954-1967.

http://dx.doi.org/10.4088/JCP.v67n1217 
[55] Lin PY, Su KP. A meta-analytic review of double-blind, placebo-controlled trials of antidepressant efficacy of omega3 fatty acids. J Clin Psychiatry 2007; 68: 1056-61. http://dx.doi.org/10.4088/JCP.v68n0712

[56] Lanquillon S, Krieg JC, Bening-Abu-Shach U, Vedder $\mathrm{H}$. Cytokine production and treatment response in major depressive disorder. Neuropsychopharmacology 2000; 22: 370-9.

http://dx.doi.org/10.1016/S0893-133X(99)00134-7
[57] Bot M, Carney RM, Freedland KE, et al. Inflammation and treatment response to sertraline in patients with coronary heart disease and comorbid major depression. J Psychosom Res 2011; 71: 13-7.

http://dx.doi.org/10.1016/j.jpsychores.2010.11.006 